\title{
Correcting for Survey Effects in Pre-election Polls
}

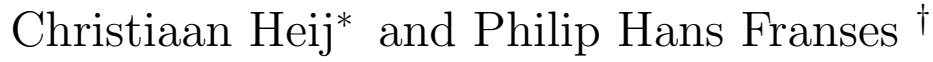 \\ Erasmus University Rotterdam \\ Econometric Institute Report EI2010 - 20
}

\begin{abstract}
Pre-election polls can suffer from survey effects. For example, surveyed individuals can become more aware of the upcoming election so that they become more inclined to vote. These effects may depend on factors like political orientation and prior intention to vote, and this may cause biases in forecasts of election outcomes. We advocate a simple methodology to estimate the magnitude of these survey effects, which can be taken into account when translating future poll results into predicted election outcomes. The survey effects are estimated by collecting survey data both before and after the election. We illustrate our method by means of a field study with data concerning the $2009 \mathrm{Eu}-$ ropean Parliament elections in the Netherlands. Our study provides empirical evidence of significant positive survey effects with respect to voter participation, especially for individuals with low intention to vote. For our data, the overall survey effect on party shares is small. This effect can be more substantial for less balanced survey samples, for example, if political orientation and voting intention are correlated in the sample. We conclude that pre-election polls that do not correct for survey effects will overestimate voter turnout and will have biased party shares.
\end{abstract}

\section{Keywords}

pre-election polls, survey effects, intention modification, self-prophecy, data collection, turnout forecast, bias correction

${ }^{*}$ Corresponding author, Econometric Institute, Erasmus University Rotterdam, P.O. Box 1738, 3000 DR Rotterdam, The Netherlands, email: heij@ese.eur.nl, fax: +31-10-4089162, tel: $+31-10-4081277$.

$\dagger$ The authors thank Peter Clarijs and Bas Hogeling for their help in a pilot study and they thank Joyce Bertens, Johan Heikoop, Geert Stapensea, and Joris Wagenaar for their assistance in carrying out the surveys. 


\section{Introduction}

Forecasting voting behavior in democratic elections is of substantial practical interest. Pre-election polls are popular sources of information in many countries, where several agencies are in competition by publishing the outcomes of political polls on a regular basis. In some cases, election forecasts seem to have a quite persistent bias. In the Netherlands, for example, the share of left-wing parties tends to be over-estimated by about 3-5 percent points. This over-estimation occurred both in the European Parliament elections of 2009 (with a predicted share of left-wing parties of $32.7 \%$, as opposed to an actual share of $28.1 \%$ ) and in the preceding regional elections of 2007 (predicted about $42 \%$, actual $38.8 \%$ ).

The finding that election forecasts often do not match well with actual election outcomes may be caused by several factors. For example, political sentiments can change in the days that lie between the date of the survey and the date of the election. This effect can be reduced by taking polls on a regular basis, for instance weekly, and by continuing the polls until only shortly before the day of the election. It may also be that the survey sample is not sufficiently representative or that the survey questions cause certain biases. Some people may wish not to respond, resulting in non-response bias, and others may answer incorrectly. Such response bias may be conscious or unconscious, for instance, because the respondent commits to the interviewer. These effects can all be mitigated by a careful design of the survey questionnaire and by the way the survey is performed.

In this paper, we investigate another possible cause of forecast bias, that is, that interviewed individuals may change their ultimate voting behavior in response to the interview. The mere act of asking someone to participate in a pre-election poll may indeed change the voting behavior. It may well be that the poll does not influence all potential voters in the same way. In that case, the very act of surveying automatically causes that the survey group is not representative, as the resapondents in the survey are subjected to psychological effects that are not present in the rest of the population. This implies that the survey outcomes can not be extrapolated to the population in a straightforward way. In particular, surveys may over-estimate turnout behavior, as individuals who otherwise would not have voted may be activated to do so, and, in addition, respondents may misreport their actual behavior due to social desirability effects. Several studies indicate that voter participation may indeed be overestimated due to survey effects, see, for example, Traugott and Katosh (1979), Greenwald et al (1987), and Granberg and Holmberg (1992). It is important to take such psychological effects into account, and we will do so too, as these effects influence the outcomes of opinion polls.

The phenomenon that surveys may cause similar effects in (a priori) stated intended behavior and (a posteriori) reported behavior is known under various 
names in the social sciences literature. Sherman (1980) introduced the term 'self-erasing' effect, as survey effects may be not be detected if the effect of increased voting intentions of surveyed persons is masked by their higher participation rates. As pre-election polls may cause respondents to over-report their prior voting intentions as well as their actual voting behavior, in order to show behavior that is consistent with expressed intentions, this is also called a 'self-prophecy' effect by, among others, Greenwald et al (1987) and Smith et al (2003). This phenomenon is also labeled as 'self-generated validity', see, for instance, Feldman and Lynch (1988) and Chandon et al (2005). In this paper, we study the presence and magnitude of survey effects on voter turnout and on party choice, and we investigate whether these effects depend on personal characteristics like prior intentions and political orientation. Such insights help to correct survey outcomes for these survey effects.

Basically, there are two possible ways to reduce self-prophecy effects. The first is to try to construct questionnaires that minimize the psychological impact on subsequent behavior. We refer to Belli et al (1999) and Brian et al (2007) for contributions on survey question wording that reduce the bias in self-reported voting behavior. A second way, which we will adopt in this paper, is to estimate the magnitude of these effects so that one can use these for correcting the bias.

The data are obtained from a field study in the Netherlands concerning the June 2009 elections for the European Parliament. The survey effects are identified by collecting data from two groups, a treatment group and a control group. Respondents in both groups are interviewed twice. The first survey consists of a face-to-face interview and takes place before the election, whereas the second interview is done by telephone or e-mail after the election. The first interview differs between the two groups, with questions on the upcoming election in the treatment group and with questions on the international financial crisis in 2009 in the control group. Therefore, the voting behavior may be affected by the survey in the treatment group, but not in the control group. After the election, the second interview asks for the actual voting behavior, and it contains additional questions for the control group to obtain the same information set as for the treatment group. Relevant control variables include previous political choice and socioeconomic and demographic background. This information is used to evaluate in which way participating in the survey affects voter turnout and party choice. The novelty of our study is that the thus obtained correction factors may be of help in future polls to get more reliable forecasts of actual election outcomes. Stated more precisely, the results of Table 4 can be used to correct for survey effects, provided that information is available on the political orientation of respondents and, if possible, on voting intention factors. This may be of interest, for example, for agencies involved in political polls as well as for political journalists and campaign managers.

Our paper is organized as follows. Section 2 provides details on the method of 
data collection and it contains summary statistics of the data. Section 3 discusses our models, consisting of a binary logit model to predict voter turnout and a multinomial logit model for party choice (with four choice options: vote for a left-wing, a middle, or a right-wing party, and other, including the decision not to vote). Section 4 presents the results, including estimates of the survey effects on participation rates and on party choice. Section 5 concludes with a summary of our findings and with topics for further research.

\section{Data}

\subsection{Design of field study}

To investigate the potential effects of surveys on voting decisions, we use the well-known methodology of using treatment and control groups. As intended behavior has to be compared with actual behavior, both groups are surveyed before ('ex ante') and after ('ex post') the election. There are four survey groups in total, which we denote by 'ex ante treatment', 'ex ante control', 'ex post treatment', and 'ex post control'.

In the ex ante treatment group, the survey questionnaire is related explicitly to the then upcoming election for the European Parliament on June 4, 2009. Respondents were asked to answer a list of questions on their political interests, their voting decisions at previous elections, their inclination to participate in the upcoming election, and their preferred political party, as well as some personal questions concerning age, education, income, and work. In the ex ante control group, however, the questions are related to the financial crisis that dominated the news in 2009 and that caused much uncertainty due to collapsing banks, a world-wide recession, and increasing unemployment. Apart from this difference in topics, the surveys in the ex ante treatment and control groups are performed in exactly the same way. Both surveys were performed in the same week (about two weeks prior to the election), in the same manner (face-to-face interview performed by two students). We made also sure to use the same sample selection method in both groups. More than fifty teams, each consisting of two of our undergraduate students in econometrics, collected twenty surveys each, resulting in 1056 responses, with 549 in the treatment group and 507 in the control group. The teams proposed alternative locations for their surveys, varying from sport facilities to elderly homes and from poor neighborhoods in large cities to small villages in rural areas. The selection of locations was explicitly coordinated to get sufficient variation in the data, together with a reasonable degree of representativeness of both samples as far as geographical region and social and demographic conditions is concerned.

After the election, the respondents were contacted by email or by telephone. In the ex ante surveys, the students had to ask respondents for this informa- 
tion, stating that this was required by the university in order for us to be able to check the validity of the work of the students. Therefore, respondents were prepared to be contacted again. To their surprise, the purpose was not only to check if they had participated in the survey but also to pose them some additional questions. The ex post treatment survey consists of only two questions, on voter participation and on party choice. The ex post control questionnaire is more extensive and contains eight questions. This longer list of questions is needed to get relevant information that had to be excluded from the ex ante control survey, in order to prevent any (election) treatment effect in this group. In both groups, the information on voting behavior is obtained from self-reports, as there exist no other means to get this type of information.

The survey information that will be used in our analysis is summarized in Table 1. ${ }^{1}$ This table also shows the variable names that will be used throughout this paper, as well as their meaning and their relation to the survey questions.

\section{Table 1 to be included about here.}

\subsection{Turnout and party shares}

The main condition needed for our study is that the treatment and control groups should be similar, apart from differences in the questions of the surveys in each group. Both survey groups are rather similar in terms of personal characteristics (gender, age, and education). Both groups differ in some respects from the Dutch population of potential voters, due to an over-representation of males (of about 5-10\%), of persons below the age of 40 (of about 15-20\%), and of the higher educated (of about 5-10\%). This may be caused by selection effects, as the surveys were performed by our students, most of whom are male, about 20 years old, and belonging to a class of the higher educated. However, the main condition that the treatment and control groups have similar characteristics is met. ${ }^{2}$

\section{Table 2 to be included about here.}

The main outcomes on turnout and party choice are summarized in Table 2. The reported turnout is about $60 \%$ in both ex post samples, whereas the actual turnout is less than $40 \%$. It seems therefore that the higher turnout in the samples is mostly due to the self-reported nature of this figure, and not so much due to 'self-prophecy' effects in the treatment group. Our finding is thus in line with the results of Bernstein et al (2001) and Traugott and Katosh (1979), who also find an over-reporting gap of about $20 \%$ points (reported $70 \%$, as opposed to real 50\%). Our finding differs from that of Gerber and Green (2001), who do not find an indication that phone calls increase voter

\footnotetext{
${ }^{1}$ The four questionnaires are shown in full detail in Appendix A.

${ }^{2}$ Further details on personal characteristics are in Table 5.
} 
turnout. However, our study differs in two respects from Gerber and Green (2001), as our ex ante surveys are face-to-face and the voter turnout of the ex post surveys is self-reported. Our results amend some previous discussions on 'self-prophecy' effects of surveys. For instance, Greenwald et al (1987) report 'self-prophecy' effects of 10-25\% for their sample of 60 undergraduate students, whereas Smith et al (2003) did not find such self-prophecy increased voter turnout in their sample of households. ${ }^{3}$ Smith et al (2003) find also no support for the suggestion raised in Greenwald et al (1988) that self-prophecy effects may be smaller for persons with an especially strong or weak past voting record, whereas those with a moderate behavior may be swayed most by self-prophecy. As we will see in Section 4, our study finds that survey effects depend on voting intentions and that the activation effect on voter turnout is stronger at lower intention levels.

Table 2 contains also information on refusal rates and non-response. The refusal rates in the ex ante surveys vary between 20-27\%. Most people refused because of time limitations, and only a small portion refused because of the requirement to provide contact information. In general, the far majority of people were readily available to cooperate in order to help the students to get their work done. The refusal rates in the ex post samples are very small, about $1 \%$, caused by the unpleasant surprise of additional questions. However, the non-response rates are high in the ex post samples, $34 \%$ in the treatment group and even $54 \%$ in the control group. This high non-response is partly due to wrong contact information, but mostly to unwillingness to cooperate. This may be due to the confidential nature of actual voting behavior. Another factor is the time it takes to answer the ex post survey, as the non-response of the control group (54\%, for eight questions) is considerably higher than that of the treatment group (34\%, for two questions). This finding confirms the result of Galesic and Bosnjak (2009) that response rates are lower for longer questionnaires.

The upper part of Table 2 shows party shares for the actual election as well as for a leading polling agency and for our ex ante treatment sample and our two ex post samples. As more than ten Dutch political parties participated in the election, the eight main parties are grouped in three blocks: left-wing (Green Left, Socialist Party, and Labour Party), middle (Democrats 66 and Christian Democrats), and right-wing (Christian Union - Reformed Party, Liberals, and Party for Freedom). The other, much smaller parties have a combined share

\footnotetext{
${ }^{3}$ Apart from the 'out-door' surveys that are reported here, we also performed all four types of survey 'in-door', with relatively smaller and much more homogenous samples of students. These students answered in an anonymous way (written answers on coded forms, without contact information, so that 'self-prophecy' effects are mitigated). Moreover, these students are very well accustomed to being surveyed (so that the treatment effects are mitigated). Even under these less obtrusive conditions, the reported turnout of $61 \%$ in the treatment group and $71 \%$ in the control group is still much higher than the actual turnout of the younger, as reported after the election in the media.
} 
of about $5 \%$ of the votes and are not considered separately in the sequel. The actual share of left-wing parties is 1-4\% smaller than predicted, and the actual share of other parties is 1-3\% larger than predicted. For our purposes, the most important finding is that the party shares in our samples are close to or even somewhat more accurate than those predicted by the leading polling agency. This means that, as far as reported intended party choice is concerned, our samples collected by untrained students are at least not worse than those collected by a professional agency.

\section{Table 3 to be included about here.}

In order to get a first rough idea of survey effects on voter participation and party choice, we compare the self-reported percentages in the ex post treatment and control groups of four alternative choices, that is, not to vote, or to vote for a left-wing, middle, or right-wing party. As the political orientation of the respondent is an obvious conditioning factor for this choice, we consider these percentages also for three sub-groups, that is, for left-wing, middle, and right-wing oriented persons. The results are in Table 3 . At the $5 \%$ significance level, the only significant treatment effect is an increase in voter participation of left-wing oriented persons by about $17 \%$ points, from $54 \%$ in the control group to $71 \%$ in the treatment group. About one half of the extra votes are for left-wing parties, and the other half is divided equally among middle and right-wing parties. Persons with a middle political orientation are somewhat de-activated by the poll ( $8 \%$ reduction in participation), but this effect is not significant. For a proper interpretation of these results, the other relevant conditioning variables should of course take comparable values in both ex post samples. Indeed, the average levels of the variables Voting Intention, Voting Attitude, Previous Voting, and Political Interest are very much the same in both groups, and the same holds true for the party shares. ${ }^{4}$

\section{Models}

\subsection{Voting participation model}

The decision whether or not to participate in voting depends on many factors, of which some are observed and others are latent. The ex ante treatment survey contains an explicit question on voting intention ${ }^{5}$, (with answers ranging from $1=$ 'no, certainly not' to $7=$ 'yes, absolutely certain'). This information is, of course, not available in the ex ante control group. In principle, the ex post control survey could ask for prior voting intentions, but it will be very hard for respondents after the election to recall the intentions they had some weeks before the election took place. Therefore, the voting intentions in the

\footnotetext{
${ }^{4}$ Table 6 contains a detailed comparison of treatment and control groups.

${ }^{5}$ Question 6, see Appendix A
} 
treatment group are explained in terms of factors that are available also for the control group. These factors can then be used to estimate the voting intentions for the control group. This strategy to deal with missing intention information in the control group is inspired by similar ideas in Chandon et al (2005).

Several factors may affect voting intentions, such as past voting attitudes, interest in politics, political orientation, age, education, income, and so on. We applied a backward selection strategy for the factors in regression models to explain Voting Intention. ${ }^{6}$ That is, we started with all potentially relevant factors and removed the least significant factors one by one until all remaining factors are significant (at a 5\% significance level). Three factors remain, that is, in decreasing order of importance: Voting Attitude, Previous Voting, and Political Interest. This confirms Murray et al (2009), who propose two survey items to identify likely voters, that is, vote intent and previous voting. ${ }^{7}$

For every respondent with known scores for Voting Attitude, Previous Voting, and Political Interest, the fitted voting intention (denoted by FVI) is computed by using the regression coefficients as weights. This information can be obtained for 464 respondents in the ex ante treatment survey and for 191 respondents in the ex post control survey. Voting Intention is measured on a 7-point scale, and FVI ranges between 1.4 and 6.7, with mean 5.3, median 5.7, and standard deviation 1.4. The FVI scores do not differ significantly between treatment and control group, and also not between different political orientation groups. ${ }^{8}$ There are only two sub-groups for which the mean FVI differs significantly between the treatment and control groups. ${ }^{9}$ First, the FVI of non-voters is significantly larger in the treatment group than in the control group. A possible explanation is that FVI is computed from the ex ante survey in the treatment group, and from the ex post survey in the control group. It may well be that, before the election, individuals who will actually not vote still report higher intention levels than what is reported after the election by actual non-voters, due to a 'self-erasing' effect to justify own behavior. Second, the FVI of right-wing voters is significantly smaller in the treatment group than in the control group. A possible explanation is that non-response in the ex post control group is considerable $(20 \%$ points more than in the treatment group, see Table 2), and the willingness to respond may well be correlated positively with voting attitudes and political interest, and hence with FVI.

\footnotetext{
${ }^{6}$ Names in capitals refer to the variables as defined in Table 1.

${ }^{7}$ Details of the estimated regression model are in Section 4, see also Tables 7 and 11.A.

${ }^{8}$ Details of these tests are in Table 11.B. The result that FVI is not related to Political Orientation is important for the following reason. As we will see later in Table 4, voting decisions are modeled in terms of these two factors, see also Table 10. The lack of correlation allows us to to obtain single-factor effects in a simple way, for Political Orientation by aggregating over FVI, and for FVI by aggregating over Political Orientation.

${ }^{9}$ Details can be found in Table 11.C.
} 
The next step is to model the voting participation decision in terms of explanatory factors, including voting intentions. The individual decision whether or not to participate in the election is obtained from the ex post surveys. ${ }^{10}$ The set of explanatory factors is weighted to get a voting index score, say, $\mathrm{V}=\beta_{1} x_{1}+\ldots+\beta_{k} x_{k}$, where factor $x_{i}$ has weight $\beta_{i}$. The binary logit model uses the following expression for the voting participation probability: Prob(vote) $=e^{V} /\left(1+e^{V}\right)$. The explanatory factors are chosen by a backward selection strategy. The resulting model contains the following factors to explain voter participation: fitted voting intention (FVI), Political Orientation, Treatment (a dummy variable, with value 1 in the treatment group and value 0 in the control group), and interaction terms of Treatment with FVI and Political Orientation. ${ }^{11}$ We will also use a simpler version of this model that is obtained by excluding FVI, which is relevant in situations where information on voting intentions is not available. The interaction of Treatment with the other two factors is needed to account for possible differences in the effect of these factors in the treatment and control groups.

We choose to use the fitted voting intention (FVI) in both the treatment and the control group, even though the treatment survey contains an explicit question on Voting Intention. The motivation for this choice is two-fold. First, it is simpler to use the same variable in both groups, as this prevents difficulties in interpretation due to differences in variables between the two groups. Second, if the data are restricted to the treatment group, logit models with FVI give similar results as logit models with Voting Intention, so that both variables play a similar role. ${ }^{22}$ Another issue worth considering here is the possible endogenous nature of FVI, as this constructed voting intention may be a noisy measure of the true, latent intention. We used the method proposed by Rivers and Vuong (1988) to test for the presence of measurement errors, see also Wooldridge (2002). For our survey data, endogeneity appears not to be significant (even at the $10 \%$ significance level). ${ }^{13}$ This means that FVI can be treated in the same way as any other (directly observed) factor in the employed logit models.

\subsection{Party choice model}

The voting participation decision is binary ('yes' or 'no') and, as discussed in the preceding section, this decision is modeled in terms of the fitted voting intention (FVI), Political Orientation, a treatment dummy, and interaction terms of this dummy with FVI and Political Orientation. The positive participation decision ('yes') can be refined by distinguishing between the parties

\footnotetext{
${ }^{10}$ Question 15, see Appendix A.

${ }^{11}$ Details of the estimated logit model are in Section 4, see also Tables 8 and 12.A.

${ }^{12}$ See Table 12.C.

${ }^{13}$ See Table 12.B.
} 
voted for. The ex post surveys asked for this information ${ }^{14}$, with a total of eight parties to choose from. For simplicity, the parties are combined in three blocks, left-wing (Green Left, Socialist Party, and Labour Party), middle (Democrats 66 and Christian Democrats), and right-wing (Christian Union - Reformed Party, Liberals, and Party for Freedom). This set-up results in four choice options: not to vote, or to vote for a left, middle, or right party. We employ a multinomial choice model, extending the binary logit model to the multinomial logit model. Whereas the binomial model with two choice options is defined in terms of a single index score, the multinomial model with four choice options is defined in terms of three index scores, one for left parties $(L)$, one for middle parties $(M)$, and one for right parties $(R)$. Each index score is a weighted average of the explanatory factors, say, $\mathrm{L}=\beta_{L 1} x_{1}+\ldots+\beta_{L k} x_{k}$, and similarly for $\mathrm{M}$ and $\mathrm{R}$ (with the same factors $x_{i}$, but with different weights $\beta_{M i}$ and $\left.\beta_{R i}\right) .{ }^{15}$ Our multinomial choice model contains the same factors as the binary choice model (a constant, FVI, and Political Orientation), but as the coefficients in the treatment and control groups may be different, the resulting number of factors is $k=6$ (that is, the three factors interacted with the treatment dummy). As before, we use also a simpler version of the model that is obtained by excluding FVI. ${ }^{16}$

\section{Results}

\subsection{Voting participation}

We follow the modeling strategy described in Section 3.1. The fitted voting intention (FVI) is obtained from the following equation: ${ }^{17}$

$$
\begin{aligned}
\text { FVI }= & -1.04+0.80 \times \text { Voting Attitude } \\
& +0.32 \times \text { Previous Voting }+0.21 \times \text { Political Interest. }
\end{aligned}
$$

As expected, prior voting intentions are related positively with all three explanatory factors. As each factor is measured on the same (5-point) scale, Voting Attitude ('Do you usually participate in voting or do you not?') is the most important factor.

\footnotetext{
${ }^{14}$ Question 16, see Appendix A.

${ }^{15}$ The multinomial logit model uses the following expression for the various choice probabilities, see, for instance, Franses and Paap (2001): $\operatorname{Prob}(L)=e^{L} /\left(1+e^{L}+e^{M}+e^{R}\right)$ for the probability to vote for a left party, and similarly for middle and right parties (replacing the numerator $e^{L}$ respectively by $e^{M}$ and $e^{R}$ ), and with Prob(not vote) $=$ $1-\operatorname{Prob}(L)-\operatorname{Prob}(M)-\operatorname{Prob}(R)$.

${ }^{16}$ Details of the estimated multinomial logit model are in Section 4 , see also Tables 9 and 13. The two models in Table 9 are obtained by removing insignificant terms from unrestricted models in Table 13. For instance, treatment effects turn out to be insignificant for the choice for a 'middle' party, so that the interaction terms are dropped for this option.

${ }^{17}$ See Table 7 .
} 
The binary logit model for voting participation is $\operatorname{Prob}($ vote $)=e^{V} /\left(1+e^{V}\right)$, so that the probability to vote increases for larger values of the voting index $V$. The formula for $V$ is estimated from the survey data and differs significantly between the treatment and control groups. The results are as follows ${ }^{18}$ (for simplicity, we denote Political Orientation by PO):

$$
\begin{gathered}
\text { control : } \mathrm{V}=-9.78+1.77 \times \mathrm{FVI}+0.32 \times \mathrm{PO} \\
\text { treatment }: \mathrm{V}=-2.80+0.73 \times \mathrm{FVI}
\end{gathered}
$$

As expected, voting intentions (FVI) have a positive effect on the voting index, and hence on the voting participation probability, but this relation holds more strongly in the control group than in the treatment group. Further, in the control group, the probability to vote increases for individuals who are more oriented to the right (for higher values of PO), but this effect does not exist in the treatment group (that is, this effect is not significant at the $5 \%$ level). The explicit questions on the upcoming election in the treatment group have, on average, a positive voting participation effect. For instance, at theoretical mean levels of FVI and PO (with value 4, as both variables range between 1 and 7$), V=-1.42$ in the control group and $V=0.12$ in the treatment group, corresponding to voting probabilities of respectively $19 \%$ and $53 \%$. The effect is the strongest for left oriented persons with a low intention to vote. For instance, for $\mathrm{FVI}=\mathrm{PO}=2, V=-5.60$ in the control group and $V=-1.34$ in the treatment group, corresponding to voting probabilities of respectively $0 \%$ and $21 \%$. This strong activation effect for left oriented persons is in line with the observed participation percentages in the treatment and control groups reported in Table 3, as discussed in Section 2.2. On the other hand, the treatment effect is relatively small or even slightly negative for persons with high intention to vote. For instance, for FVI $=6$ and $\mathrm{PO}=4$, we get $V=2.12$ in the control group and $V=1.58$ in the treatment group, corresponding to voting probabilities of respectively $89 \%$ and $83 \%$.

As information on voting intentions may not be readily available in election polls, it is of interest to consider also a simpler voting participation model that contains Political Orientation as the only explanatory factor. The corresponding estimated logit models provide the following formulas for the voting index $V$, which differ significantly for the two survey groups ${ }^{19}$ :

$$
\begin{aligned}
& \text { control : } \mathrm{V}=-0.53+0.27 \times \mathrm{PO} \\
& \text { treatment: } \mathrm{V}=0.82
\end{aligned}
$$

Whereas a more right-wing orientation has a positive effect on the voting probability in the control group, the political orientation has no significant effect

\footnotetext{
${ }^{18}$ See Table 8; in the treatment group, the coefficient of Political Orientation is $0.32-0.44$ $=-0.12$, and as this does not differ significantly from 0 , this variable is deleted.

${ }^{19}$ See Table 8; in the treatment group, the coefficient of PO is $0.27-0.33=-0.06$, and as this does not differ significantly from 0 , this variable is deleted.
} 
in the treatment group. The activation effect of the election poll is positive if $0.82>-0.53+0.27 \times \mathrm{PO}$, that is, if $\mathrm{PO}<5$. This means that left and middle oriented persons (with $\mathrm{PO}$ at most 4 ) are activated, right or very right oriented persons (with PO 6 or 7) are de-activated, and there is hardly any effect for individuals who report their orientation as 'more right than left' $(\mathrm{PO}=5)$. The activation effect on the left wing is, on average, larger than the de-activation effect on the right wing. For example, consider a left-wing person $(\mathrm{PO}=2)$ and a right-wing person $(\mathrm{PO}=6)$. For the left-wing person, the treatment raises $V$ from 0.01 to 0.82 and the voting participation probability from $50 \%$ to $69 \%$. For the right-wing person, the treatment causes $V$ to decrease from 1.09 to 0.82 , and the voting participation probability decreases from $75 \%$ to $69 \%$.

In summary, election polls tend to have a positive effect on voter turnout, in particular for low motivated persons with a left political orientation. This finding differs in nature from marketing survey effects as reported in Chandon et al (2005), who find that surveys increase the probability to buy for those with high latent intent, but decrease it for those with low latent intent. That is, in the marketing literature, surveys are found to strengthen the relation between latent intentions and manifest behavior. In contrast, we find that election polls have an activation effect for lowly motivated individuals and no or even slightly negative effects for the highly motivated. A possible explanation is that consumers may have strong positive or negative associations with commercial products, whereas most citizens will think positively of voting participation. This lack of negative stimuli of election polls is also supported by the sample fractions of non-voters in Table 3, see Section 2.2.

\subsection{Participation and party choice}

The previous analysis can be refined by distinguishing between party choices in the sub-group of voters, as discussed in Section 3.2. In total, there are four options to choose from: not to vote, or to vote for a left-wing, a middle, or a right-wing party. We use the data of our field study to estimate multinomial logit models for the probabilities to choose each of these four options. The explanatory factors are the same as in the previous section, that is, the fitted voting intention (FVI) and Political Orientation. As the effects of these factors may differ between the treatment and control groups, the models are specified with different coefficients for each group. As before, we consider also a simpler version, without FVI and with Political Orientation as the only explanatory factor. Because the coefficients of a multinomial logit model do not have a direct interpretation, we do not discuss these coefficients but focus instead on the corresponding choice probabilities. ${ }^{20}$ The results are shown in Table 4,

\footnotetext{
${ }^{20}$ Table 9 shows details of the models, one in terms of FVI and PO, and another in terms of PO alone. These models are obtained from more elaborate ones, after removing insignificant effects; for instance, the treatment effect is not significant for the choice "middle". Details of these more elaborate models and of the 'down-testing' steps are given in Table 13.
} 
which is obtained from models for which all coefficients are significant (at the $5 \%$ level).

\section{Table 4 to be included about here.}

We first consider the upper part of Table 4. Here, the choice probabilities depend both on prior voting intentions and on political orientation. Two levels of voting intentions, as measured by FVI, are distinguished, 'low' and 'high'. As Voting Intention ranges from 1 to 7 , we define 'Low' by FVI $=2.5$ (first quartile) and 'High' by FVI $=5.5$ (third quartile). In our sample, FVI ranges from 1.39 to 6.67 with standard deviation 1.36, so that the 'Low' and 'High' values lie about one standard deviation from the extremes of the range. For each of these two intention levels, and for each of the seven political orientation scores, the choice probabilities are computed for the treatment group and also for the control group. The differences between these two groups show the treatment effects on voting choices, and the largest of these differences (those above $5 \%$ in magnitude) are underlined in Table 4.

The main findings are the following. As expected, party choice probabilities are strongly related with political orientation. The treatment effects are stronger for low intention levels than for high intention levels. Individuals with a low intention to vote are activated to participate, both at the left wing and, even more so, on the right wing. It is no surprise that this activation is beneficial for the parties corresponding to the political orientation of the activated voters. That is, left-wing parties benefit from activated left-wing oriented individuals and right-wing parties from activated right-wing oriented individuals. At a high intention level, the activation effect is still substantial for persons oriented to the left or the very left. However, this activation effect disappears for middle and right oriented persons with a high intention level. In this sub-group, the share of left-wing votes is reduced by $5-10 \%$ points. As it is rather uncommon for middle or right-wing individuals to vote for a left party, it seems that respondents in the treatment group act more consistently in this respect than persons in the control group. Finally, when averaged over all seven levels of political orientation ${ }^{21}$, the only substantial effect that remains is the activation of lowly motivated individuals to vote for a right-wing party.

Next, we consider the bottom part of Table 4, obtained by using Political Orientation as the only explanatory factor (apart from treatment effects). The outcomes show considerable activation effects for left-wing individuals to vote for a left-wing party ${ }^{22}$, and some reduction to vote for a left-wing party for

\footnotetext{
${ }^{21}$ This is a weighted average, with the sample fractions as weights; see Table 10.A for further details.

${ }^{22}$ This result on the activation of left-wing persons replicates our earlier findings in a small-scale pilot study that was performed for regional elections in the Netherlands in 2007. Table 10.B provides further details on this study. In the pilot study, we also found a de-
} 
the middle and right-wing oriented. These results are in line with the ones obtained before, except that the activation effect of (lowly motivated) rightwing individuals to vote for a right-wing party is not found anymore. The explanation for this finding is that the voting intentions in our sample are highly skewed to the left, as only $7 \%$ of the FVI values are below 'Low' (2.5), whereas $47 \%$ of the values are larger than 'High' (5.5). This means that, in our sample, the share of highly motivated respondents is much larger than the share of lowly motivated respondents. As the variables used to compute FVI (Voting Attitude, Previous Voting, and Political Interest) are all self-reported, these relatively high intention values may be partly due to respondents giving socially desirable answers.

Even though election polls have an activating effect for left oriented persons, the overall treatment effect, after averaging over all political orientation levels, is very small. That is, the effects on turnout and on the shares of left, middle, and right parties are all less than 1\%, see the bottom row of Table 4 . It should be realized that, although this finding holds true for the sample composition of our field study, other surveys with different shares of the various intention levels and political orientations may well lead to larger biases in turnout and party shares. For samples of different composition than ours, the results of Table 4 can be used to correct for survey effects, provided that information is available on the political orientation of respondents and, if possible, on voting intention factors.

\subsection{Limitations and discussion}

The results presented above should be interpreted with some caution. The voting behavior data are self-reported and may differ from actual behavior, due to 'self-prophesy' effects. In the country under investigation, voting is anonymous, so that self-reports are the only means to obtain individual voting data. Further, attrition as measured by the non-response rates for the ex post surveys is substantial. One cause of this is that a substantial proportion of the respondents did not provide proper contact information. Another reason may be that respondents did not get any compensation for their cooperation. As the ex post control survey was relatively demanding, this may partly explain the relatively large drop-out rate of over $50 \%$ in this group.

Our study indicates that especially persons with left-wing political orientation can be motivated by a survey to participate in voting. This finding is in line with previous studies. For instance, weather conditions on the election day seem to have a stronger impact on left-wing persons than on right-wing

activation effect for right-wing persons, but this finding is not replicated in our current study. The results of the pilot study are not reliable, due to small sample sizes of about 60 observations in the treatment and control groups. 
persons. In general, right-wing individuals tend to be relatively more determined to participate in elections, so that positive and negative stimuli have a stronger effect on left-wing individuals. One of the possible explanations is a different age distribution for both wings, as right-wing persons are on average somewhat older and many of them have lived in times when voting was still obligatory.

\section{Conclusion}

The outcomes of pre-election polls may be biased for several reasons, with an important one being that the survey itself may change the behavior of respondents. We applied discrete choice models to evaluate the magnitude of survey effects on voting behavior. The data are obtained for two groups, a treatment group and a control group. Both groups are interviewed twice, once before the election and a second time after the election. Respondents in the treatment group can be influenced in their voting behavior, as their first interview is on the upcoming election. This effect is not present in the control group, as their first interview is on another topic, that is, the international financial crisis. By comparing the voting behavior in both groups, we obtain estimates of the involved survey effects.

The empirical results indicate positive survey effects on voter turnout. This means that surveyed individuals are, on average, more likely to go voting (or, at least, more likely to report having gone to vote) than those who are not surveyed. This holds true not only in the treatment group, but also in the control group, and this effect is of similar magnitude (of about $25 \%$ points) in both groups. To mitigate this bias, voter turnout predictions based on preelection polls must be corrected downwards by a considerable amount. The survey effect on participation of left-wing persons does not depend much on their prior intentions. For right-wing persons, however, the activation effect is considerable for low intention levels but negligible for high intention levels. The activation effect differs in some respects between treatment and control group, which can be interpreted as a self-prophecy effect, because the treatment group is subject to this effect but the control group not. As compared to the control group, the activation effect is about $10 \%$ points larger in the treatment group for lowly motivated persons and also for left-oriented persons. These self-prophecy effects are much smaller for highly motivated and rightwing orientated individuals.

For practical polling purposes, where intention levels are unknown, the most interesting results are possibly the ones concerning the survey effects on the shares for left-wing, middle, and right-wing parties. Our study finds the largest activation effect for left-wing voters to vote for a left-wing party. This effect is estimated to be about $20 \%$ for 'very left' persons and about $10 \%$ for 'left' 
persons. When averaged over the three left orientation classes (2\% very left, $16 \%$ left, and $18 \%$ more left than right), the effect is about $5 \%$. This bias is close to the recently observed over-estimation by about 3-5\% of the share of left-wing parties in Dutch election polls.

When averaged over all intention levels and political orientation groups (with weights obtained from the survey samples), the overall survey effects in our treatment and control groups do not differ significantly. This means that our surveys increased (reported) voter turnout, but that these surveys did not cause significant shifts in party shares. This result is in contrast with the recent over-estimation of the share of left-wing parties by Dutch polling agencies. Although somewhat speculative, we believe that this bias might be due to the fact that the employed samples of these agencies differ in composition from our sample. As discussed before, our sample is not fully representative of the population of potential voters, as, for instance, higher education levels are over-represented. On average, left-wing oriented persons have a relatively lower education than right-wing persons, so that left-wing persons may be under-represented in our sample. The presumably more representative samples of official polling agencies may therefore contain a larger share of left-wing persons than in our sample, so that the activation effect of left-wing voters is more pronounced than in our sample. This argument is only speculative, as the polling agencies do not provide the relevant information on their sampling procedures.

It is of interest to gain further experience with the methodology proposed in this paper at other elections. The obtained correction factors can then be applied to correct opinion poll responses for survey effects in order to get more accurate forecasts of the actual election outcomes. 


\section{References}

Belli, Robert F., Michael W. Traugott, Margaret Young, and Katherine A. McGonagle. 1999. "Reducing Vote Overreporting in Surveys." Public Opinion Quarterly 63: 90-108.

Bernstein, Robert, Anita Chadha, and Robert Montjoy. 2001. "Overreporting Voting." Public Opinion Quarterly 65: 22-44.

Chandon, Pierre, Vicky G. Morwitz, and Werner J. Reinartz. 2005. "Do Intentions Really Predict Behavior? Self-Generated Validity Effects in Survey Research." Journal of Marketing 69: 1-14.

Feldman, Jack M., and John G. Lynch. 1988. "Self-Generated Validity and Other Effects of Measurement on Belief, Attitude, Intention, and Behavior." Journal of Applied Psychology 73: 421-35.

Franses, Philip Hans B.F., and Richard Paap. 2001. Quantitative Models in Marketing Research. Cambridge: Cambridge University Press.

Galesic, Mirta, and Michael Bosnjak. 2009. "Effects of Questionnaire Length on Participation and Indicators of Response Quality in a Web Survey." Public Opinion Quarterly 73: 349-360.

Gerber, Alan S., and Donald P. Green. 2001. "Do Phone Calls Increase Vote Turnout?" Public Opinion Quarterly 65: 75-85.

Granberg, Donald, and Soren Holmberg. 1992. "The Hawthorne Effect in Election Studies: The Impact of Survey Participation on Voting." British Journal of Political Science 22: 240-47.

Greenwald, Anthony G., Catherine G. Carnot, Rebecca Beach, and Barbara Young. 1987. "Increasing Voting behavior by Asking People if They Expect to Vote." Journal of Applied Psychology 72: 315-8.

Greenwald, Anthony G., Mark R. Klinger, Mark E. Vande Kamp, and Katherine L. Kerr. 1988. "The Self-Prophecy Effect: Increasing Voter Turnout by Vanity-Assisted Consciousness Raising." Unpublished Manuscript, University of Washington.

Murray, Gregg R., Chris Riley, and Anthony Scime. 2009. "Pre-Election Polling: Identifying Likely Voters Using Iterative Expert Data Mining." Public Opinion Quarterly 73: 159-171.

Rivers, Douglas, and Quang H. Vuong. 1988. "Limited Information Estimators and Exogeneity Tests for Simultaneous Probit Models." Journal of Econometrics 39: 347-66. 
Sherman, Steven J. 1980. "On the Self-Erasing Nature of Errors of Prediction"." Journal of Personality and Social Psychology 39: 211-221.

Smith, Jennifer K., Alan S. Gerber, and Anton Orlich. 2003. "Self-Prophecy Effects and Voter Turnout: An Experimental Replication." Political Psychology 24: 593-604.

Traugott, Michael W., and John P. Katosh. 1979. "Response Validity in Surveys of Voting Behavior." Public Opinion Quarterly 43: 359-77.

Wooldridge, Jeffrey M. 2002. Econometric Analysis of Cross Section and Panel Data. Cambridge: MIT Press. 


\section{A Questionnaires}

The data are collected in four surveys: a treatment survey and a control survey prior to the election ('ex ante'), and a supplementary survey within both groups after the election ('ex post'). The survey questions are listed below.

An asterisk * means that the question is used in our analysis (Table 1 in Appendix B contains further details on these questions and on the variable names used in the text).

\section{Ex ante treatment survey}

\section{Introductory text}

Good morning (afternoon, evening), we are students from the Erasmus University in Rotterdam and we would like to ask you some questions on the upcoming election for the European Parliament. That is, we wish to know your opinion on Europe and on the election. Are you willing to participate in this interview? It will take less than five minutes of your time.

We will also ask you for your telephone number or email address. Our professor requires this from us as proof that this interview is genuine and not fake. Are you willing to provide this information to us? Therefore, it may be that our professor contacts you. Your answers will be treated in full confidentiality and, apart from the professor, your answers will be shared with no one else. If you wish, we can give you this letter of our professor with an official statement of confidentiality.

First we would like to ask you some questions on politics.

$Q_{1}^{*}$ What is your opinion, are you interested in politics (national, in Europe, in the rest of the world)? (5-point scale, from $1=$ no, not at all to $5=$ yes, very much)

$Q_{2}$ What is your opinion, is Europe (that is, the European Union) important for you or not? (5-point scale, from $1=$ no, not at all to $5=$ yes, very important)

$Q_{3}$ What is your opinion, is the European Union beneficial or damaging for our country? (5-point scale, from $1=$ much damage to $5=$ much profit)

$Q_{4}^{*}$ What is your own political orientation, are you oriented more to the right or more to the left? (7-point scale, with $1=$ very left, $2=$ left, $3=$ more left than right, $4=$ middle, $5=$ more right than left, $6=$ right, and $7=$ very right) 
$Q_{5}$ Do you know that soon there will be elections for the European Parliament? (4-point scale, with $1=$ no, I did not know, $2=$ well, I only had a vague idea, $3=$ yes, now that you mention it, and $4=$ yes, I know)

$Q_{6}^{*}$ What do you think, will you participate in these elections? (7-point scale, from $1=$ no, certainly not to $7=$ yes, absolutely certain)

$Q_{7}^{*}$ If you would participate in the election, for which party would you then vote (you may vote for only one party)? (8-point scale, with $1=$ 'Green Left' (most left oriented party), $2=$ 'Socialist Party', 3 = 'Labour Party', $4=$ 'Democrats 66', $5=$ 'Christian Democrats', $6=$ 'Christian Union - Reformed Party', $7=$ 'Liberals', and $8=$ 'Party for Freedom' (most right oriented party); further answer options are 'another party' and 'I don't know')

$Q_{8}^{*}$ The previous elections (regional) took place in 2007. Did you participate in those elections? (5-point scale, from $1=$ no, certainly not to $5=$ yes, certainly; another answer option is 'no, I was not yet allowed to vote at previous elections')

$Q_{9}^{*}$ What is your opinion in general on elections, do you usually participate in voting or do you not? (5-point scale, from $1=$ no, never to $5=$ yes, always; another answer option is 'no, I was not yet allowed to vote at previous elections')

Next we would like to ask you some more personal questions that are important for our research project.

$Q_{10}^{*}$ May I ask to indicate your age? (age classes: 18-23, 24-29, 30-39, 40-49, $50-59,60-69,70+)$

$Q_{11}$ Are you currently employed? (yes, full time; yes, part time for at least 18 hours per week; yes, part time for less than 18 hours a week; no)

$Q_{12}$ May I ask to indicate your monthly household income (that is, of you and of your possible partner)? Please note that this concerns your combined net income per month, after deduction of taxes. (income classes, in euro: less than $400,400-800,800-1600,1600-2800,2800-4000$, more than 4000)

$Q_{13}^{*}$ May I ask for the highest completed level of education? (5-point scale, from $1=$ lower eduction to $5=$ university)

$Q_{14}$ Finally, as said before, our professor requires some contact information from you. We guarantee full confidentiality of this information and of your answers. May we ask for your telephone number or email address?

Concluding text

Thank you very much for your cooperation, and we wish you a good day. 


\section{Ex post treatment survey}

\section{Introductory text (telephone or email message)}

The interviewer introduces herself or himself and reminds the respondent of the previous interview. The interviewer explains that two additional questions are of crucial importance for the research project. Once more, full confidentiality of the answers is guaranteed, and it is confirmed again that all personal information (phone number, email address) will be removed after this second interview.

$Q_{15}^{*}$ Did you participate in the elections for the European Parliament, last June the 4-th, or did someone else vote for you? (yes, no)

$Q_{16}^{*}$ If 'Yes': For which party did you vote? (8-point scale, from $1=$ 'Green Left' (most left oriented party) to $8=$ 'Party for Freedom' (most right oriented party), see Q7 for the eight parties; further answer options are 'another party', 'I don't know', and 'I don't wish to say')

$Q_{16}$ If 'No': What is the reason that you did not participate? (voting is useless, I was not in the country at that time, I did not have time to vote, I forgot to vote, I had another reason)

\section{Concluding text}

Thank you very much for your cooperation, and we wish you a good day. 


\title{
Ex ante control survey
}

\author{
Introductory text
}

Good morning (afternoon, evening), we are students from the Erasmus University in Rotterdam and we would like to ask you some questions on the current world-wide financial crisis. That is, we wish to know what consequences this crisis has for you. Are you willing to participate in this interview? It will take less than five minutes of your time.

We will also ask you for your telephone number or email address. Our professor requires this from us as proof that this interview is genuine and not fake. Are you willing to provide this information to us? Therefore, it may be that our professor contacts you. Your answers will be treated in full confidentiality and, apart from the professor, your answers will be shared with no one else. If you wish, we can give you this letter of our professor with an official statement of confidentiality.

First we would like to ask you some questions on the economic conditions and the financial crisis.

$Q_{1}$ What is your opinion, are you interested in economic issues (national or in the rest of the world)? (5-point scale, from $1=$ no, not at all to $5=$ yes, very much)

$Q_{2}$ What is your opinion, is the current financial crisis important for you or not? (5-point scale, from $1=$ no, not at all to $5=$ yes, very important)

$Q_{3}$ What is your opinion, does the current financial crisis affect you personally? (5-point scale, from $1=$ no, not at all to $5=$ yes, very much)

$Q_{4}$ If the financial crisis can have effects for you, which possible consequences do you then fear most? (loss of job, loss of money (savings, stocks and bonds), mortgage costs or loss of own house, other)

$Q_{5}$ Did you change any of your behavior because of the financial crisis (for instance, by postponing or reducing your spending for consumption and holidays)? (5-point scale, from $1=$ no, not at all to $5=$ yes, very much)

$Q_{6}$ According to you, who should solve the financial crisis? (banks, national politics, Europe, global world, everyone on his or her own, don't know)

$Q_{7}$ Are you confident that politics (national and European) can, in general, offer solutions for the problems facing us now? (5-point scale, from $1=$ very little confidence to $5=$ very much confidence)

$Q_{8}$ What is your opinion, is the Euro currency beneficial for or damaging to our country in this financial crisis? (5-point scale, from $1=$ much damage to 5 = much profit; another answer option is 'I don't know') 
$Q_{9}^{*}$ What is your own political orientation, are you oriented more to the right or more to the left? (7-point scale, with $1=$ very left, $2=$ left, $3=$ more left than right, $4=$ middle, $5=$ more right than left, $6=$ right, and $7=$ very right)

Next we would like to ask you some more personal questions that are important for our research project.

Questions $Q_{10}$ to $Q_{14}$ are the same as the ones for the ex ante treatment group. 


\section{Ex post control survey}

\section{Introductory text (telephone or email message)}

The interviewer introduces herself or himself and reminds the respondent of the previous interview. The interviewer explains that some additional questions are of crucial importance for the research project and that this second interview will take about two minutes. Once more, full confidentiality of the answers is guaranteed, and it is confirmed again that all personal information (phone number, email address) will be removed after this second interview.

The eight questions are the ones needed to obtain the same relevant information as is available for the treatment group, that is:

$$
Q_{1}^{*}, Q_{2}, Q_{3}, Q_{4}^{*}, Q_{8}^{*}, Q_{9}^{*}, Q_{15}^{*} \text {, and } Q_{16}^{*} .
$$

Note that question $Q_{9}^{*}$ in the control group is the same as question $Q_{4}^{*}$ in the treatment group. 


\section{B Tables}

- Table 1: Survey question topics and list of variables.

- Table 2: Actual, predicted, and reported percentages of votes.

- Table 3: Voting decisions and political orientation.

- Table 4: Estimated treatment effects on voting decisions. 
Table 1: Survey question topics and list of variables

\begin{tabular}{|c|c|c|c|c|c|c|}
\hline Question topic & Question $(a)$ & Answer options & Scale & Variable name & Treatment $(b)$ & Control $(b)$ \\
\hline \multicolumn{7}{|l|}{ Personal } \\
\hline Gender & -- & Female -- Male & $0--1$ & Gender & A & A \\
\hline Age & Q10 & Below 23 -- Over 70 & $1--7$ & Age & A & A \\
\hline Highest completed education & Q13 & Primary -- University & $1--5$ & Education & A & A \\
\hline \multicolumn{7}{|l|}{ Attitude } \\
\hline Interest in political issues & Q1 & No, not at all -- Yes, very much & $1--5$ & Political Interest & A & $\mathrm{P}$ \\
\hline Voting intention & Q6 & No, certainly not -- Yes, absolutely & $1--7$ & Voting Intention & A & $\mathrm{X}$ \\
\hline Participation at the previous election & Q8 & No, cetainly not -- Yes, certainly (c) & $1--5$ & Previous Voting & A & $\mathrm{P}$ \\
\hline Usual participation in elections & Q9 & No, never -- Yes, always (c) & $1--5$ & Voting Attitude & A & $\mathrm{P}$ \\
\hline Political orientation & Q4 & Very left -- Very right & $1--7(d)$ & Political Orientation & A & A \\
\hline Preferred party if one had to vote & Q7 & Left parties -- Right parties & $1--8(e)$ & Intended Party Choice & A & $\mathrm{X}$ \\
\hline \multicolumn{7}{|l|}{ Decision } \\
\hline Participation at current elections & Q15 & No -- Yes & $0--1$ & Vote & $\mathrm{P}$ & $\mathrm{P}$ \\
\hline If participated, party actually voted for & Q16 & Left parties -- Right parties & $1--8(e)$ & Actual Party Choice & $\mathrm{P}$ & $\mathrm{P}$ \\
\hline
\end{tabular}

Notes

a. The question numbers refer to the survey questionnaires; the surveys contain several additional questions that will not be used in the analysis; for example, the ex ante control survey contained a list of questions on the financial crisis of 2008-2009.

b. The columns for Treatment and Control show whether the question was posed in the ex ante survey (A, before the elections), the ex post survey (P, after the elections), or not (X).

c. For Previous Voting and Voting Attitude, another answer option is "No, I was not yet allowed to vote at previous elections".

d. For Political Orientation, the subgroup "Left" is defined by answers 1--3 (very left, left, more left than right), "Middle" by 4 (middle), and "Right" by 5--7 (more right than left, right, very right).

e. For Intended and Actual Party Choice, 1 = Green Left, 2 = Socialist Party, 3 = Labour Party, 4 = Democrats 66, 5 = Christian Democrats, 6 = Christian Union and Reformed Party, 7 = Liberals, 8 = Party for Freedom; other answer options are "Other party" and "I don't know". 
Table 2: Actual, predicted, and reported percentages of votes

\begin{tabular}{|c|c|c|c|c|c|c|c|c|}
\hline Party group & Dutch party names & $\begin{array}{c}\text { Actual seats } \\
\text { European Parl. }\end{array}$ & Actual \% $(b)$ & $\begin{array}{c}\text { Barometer }(a) \\
\text { Ex ante \% } \\
\end{array}$ & $\begin{array}{l}\text { Treatment } \\
\text { Ex ante \% }\end{array}$ & $\begin{array}{c}\text { Control } \\
\text { Ex Ante \% }\end{array}$ & $\begin{array}{l}\text { Treatment } \\
\text { Ex post \% }\end{array}$ & $\begin{array}{c}\text { Control } \\
\text { Ex post \% }\end{array}$ \\
\hline$\overline{\text { Left }}$ & GL, SP, PvdA & 8 & 28.1 & 32.7 & 30.7 & -1 & 33.9 & 29.0 \\
\hline Middle & D66, CDA & 8 & 31.4 & 30.0 & 32.1 & . & 30.7 & 32.3 \\
\hline Right & CU-SGP, VVD, PVV & 9 & 35.2 & 33.7 & 35.2 & . & 33.1 & 34.1 \\
\hline Other $(c)$ & Various & 0 & 5.4 & 3.6 & 2.0 & . & 2.4 & 4.6 \\
\hline \multicolumn{2}{|l|}{ Turnout } & & 36.8 & & 69.0 & 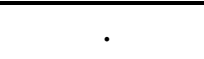 & 63.0 & 60.0 \\
\hline \multicolumn{2}{|c|}{ Sample size $(d)$} & & & . & 549 & 507 & 357 & 223 \\
\hline \multicolumn{2}{|l|}{ Refusal rate } & & & $\cdot$ & 26.8 & 20.3 & 0.9 & 1.4 \\
\hline \multicolumn{2}{|c|}{ Nonresponse $(e)$} & & & & & . & 34.0 & 53.5 \\
\hline \multicolumn{2}{|l|}{ Date (2009) } & & Jun 4 & May 20 & May15-22 & May15-22 & Jun5-Jul31 & Jun5-Jul31 \\
\hline
\end{tabular}

\section{Notes}

a. "Barometer" is a leading polling agency in the Netherlands.

b. Actual percentages are taken from http://www.europarl.europa.eu/parliament/archive/elections2009/en/netherlands_en.html

c. In the treatment and control groups, people answering the political party question by "I don't know or I don't wish to say" art excluded.

d. The reported sample sizes are for respondents answering the complete questionnaire (excluding refusals and non-response).

e. Ex post nonresponse includes respondents who provided non-operating contact information, or who did not answer the complete questionnaire. 
Table 3: Voting decisions and political orientation

\begin{tabular}{|c|c|c|c|c|c|c|c|c|c|c|c|c|}
\hline \multirow[b]{2}{*}{ Political Orientation } & \multicolumn{4}{|c|}{ Votes in Treatment Group } & \multicolumn{4}{|c|}{ Votes in Control Group } & \multicolumn{4}{|c|}{ "Difference (Treatment - Control) } \\
\hline & Not & Left & Middle & Right & Not & Left & Middle & Right & Not & Left & Middle & Right \\
\hline$\overline{\text { Left }}$ & 29.0 & 41.9 & 17.1 & 8.5 & 45.8 & 35.4 & 13.4 & 4.9 & $-16.8^{*}$ & 6.5 & 3.7 & 3.7 \\
\hline Middle & 51.5 & 9.4 & 26.0 & 9.4 & 43.4 & 6.1 & 26.5 & 20.4 & 8.1 & 3.3 & -0.5 & -11.0 \\
\hline Right & 33.3 & 3.1 & 18.0 & 43.0 & 33.3 & 10.1 & 19.0 & 35.4 & 0.0 & -7.0 & -1.0 & 7.5 \\
\hline Total & 37.0 & 18.2 & 19.9 & 21.7 & 39.9 & 19.4 & 18.5 & 19.9 & -2.9 & -1.2 & 1.5 & 1.8 \\
\hline
\end{tabular}

Notes

a. The data consist of the ex post treatment and ex post control samples.

b. The distinction between left, middle and right for Political Orientation (1-7, left-right) and Vote (party choice, 1-8, left-right) is defined as follows (see Table 1 for further details): Political Orientation is left (1-3), middle (4), or right (5-7), and Vote is left (1-3), middle (4-5), or right (6-8).

c. For each political orientation group (row), the columns show the percentages of four voting decisions (the four percentages do not add up to $100 \%$, as about $3 \%$ of the people answered by "I don't know or I don't wish to say" or by "I voted for another party")

d. A * denotes a difference between the treatment and control groups that is significant at a 5\% significance level. 


\section{Table 4: Estimated treatment effects on voting decisions}

\begin{tabular}{|c|c|c|c|c|c|c|c|c|c|c|c|c|c|}
\hline \multirow[b]{2}{*}{ Intention } & \multirow[b]{2}{*}{ Pol. Or. } & \multicolumn{4}{|c|}{ "Voting Percentages Treatment Group } & \multicolumn{4}{|c|}{ "Voting Percentages Control Group } & \multicolumn{4}{|c|}{ "Difference (Treatment - Control) } \\
\hline & & Not & Left & Middle & Right & Not & Left & Middle & Right & Not & Left & Middle & Right \\
\hline \multirow[t]{7}{*}{ Low } & 1 & 80.3 & 15.5 & 3.1 & 1.1 & 89.1 & 7.4 & 3.4 & 0.0 & -8.8 & 8.1 & -0.3 & 1.1 \\
\hline & 2 & 88.3 & 6.1 & 3.4 & 2.2 & 91.8 & 4.6 & 3.5 & 0.1 & $\overline{-3.5}$ & $\overline{1.5}$ & -0.1 & 2.2 \\
\hline & 3 & 90.0 & 2.3 & 3.4 & 4.3 & 93.5 & 2.9 & 3.6 & 0.1 & -3.4 & -0.6 & -0.1 & 4.2 \\
\hline & 4 & 88.0 & 0.8 & 3.4 & 7.8 & 94.5 & 1.8 & 3.6 & 0.2 & $\underline{-6.4}$ & -1.0 & -0.2 & $\underline{7.6}$ \\
\hline & 5 & 82.8 & 0.3 & 3.2 & 13.8 & 95.0 & 1.1 & 3.6 & 0.4 & $-\overline{-12.2}$ & -0.8 & -0.5 & $\overline{13.5}$ \\
\hline & 6 & 73.9 & 0.1 & 2.8 & 23.2 & 95.1 & 0.7 & 3.6 & 0.7 & -21.1 & -0.6 & -0.8 & 22.5 \\
\hline & 7 & 61.5 & 0.0 & 2.3 & 36.2 & 94.8 & 0.4 & 3.6 & 1.2 & -33.3 & -0.4 & -1.3 & $\overline{34.9}$ \\
\hline \multirow[t]{7}{*}{ High } & 1 & 12.1 & 78.0 & 9.0 & 0.9 & 21.7 & 60.5 & 16.2 & 1.6 & -9.6 & 17.5 & -7.2 & -0.7 \\
\hline & 2 & 23.8 & 55.3 & 17.7 & 3.2 & 28.0 & 47.3 & 20.8 & 3.9 & $\overline{-4.2}$ & $\overline{8.0}$ & $\overline{-3.1}$ & -0.7 \\
\hline & 3 & 35.2 & 29.6 & 26.2 & 9.0 & 33.0 & 33.8 & 24.6 & 8.6 & 2.3 & $-\overline{-4.2}$ & 1.7 & 0.3 \\
\hline & 4 & 39.6 & 12.0 & 29.5 & 18.9 & 35.0 & 21.8 & 26.1 & 17.2 & 4.6 & -9.8 & 3.4 & 1.7 \\
\hline & 5 & 36.4 & 4.0 & 27.1 & 32.6 & 32.8 & 12.4 & 24.5 & 30.3 & 3.5 & $\overline{-8.4}$ & 2.6 & 2.3 \\
\hline & 6 & 28.9 & 1.1 & 21.5 & 48.5 & 27.0 & 6.2 & 20.1 & 46.8 & 1.9 & $\overline{-5.0}$ & 1.4 & 1.8 \\
\hline & 7 & 20.3 & 0.3 & 15.1 & 64.2 & 19.5 & 2.7 & 14.5 & 63.3 & 0.9 & $\overline{-2.4}$ & 0.7 & 0.9 \\
\hline Low & All & 84.7 & 2.0 & 3.2 & 10.1 & 93.9 & 2.2 & 3.6 & 0.3 & $\underline{-9.3}$ & -0.2 & -0.4 & $\underline{9.9}$ \\
\hline High & All & 33.2 & 20.0 & 24.7 & 22.2 & 31.4 & 24.3 & 23.3 & 21.0 & $\overline{1.8}$ & -4.3 & 1.4 & $\overline{1.1}$ \\
\hline \multirow[t]{7}{*}{ Excluded } & 1 & 16.4 & 74.9 & 7.9 & 0.8 & 31.1 & 52.4 & 15.0 & 1.4 & -14.8 & 22.6 & -7.1 & -0.7 \\
\hline & 2 & 30.6 & 51.9 & 14.7 & 2.8 & 38.6 & 39.3 & 18.6 & 3.5 & $\overline{-8.0}$ & $\overline{12.6}$ & $\overline{-3.9}$ & -0.7 \\
\hline & 3 & 43.6 & 27.5 & 21.0 & 7.9 & 43.8 & 27.1 & 21.1 & 7.9 & -0.2 & 0.4 & -0.1 & 0.0 \\
\hline & 4 & 48.2 & 11.3 & 23.2 & 17.2 & 45.2 & 16.9 & 21.8 & 16.1 & 3.1 & -5.6 & 1.5 & 1.1 \\
\hline & 5 & 44.0 & 3.8 & 21.2 & 31.0 & 41.4 & 9.4 & 20.0 & 29.2 & 2.6 & $\overline{-5.6}$ & 1.2 & 1.8 \\
\hline & 6 & 34.4 & 1.1 & 16.6 & 47.9 & 33.2 & 4.6 & 16.0 & 46.2 & 1.2 & $\overline{-3.5}$ & 0.6 & 1.7 \\
\hline & 7 & 23.6 & 0.3 & 11.4 & 64.8 & 23.2 & 1.9 & 11.2 & 63.7 & 0.4 & -1.7 & 0.2 & 1.1 \\
\hline Excluded & All & 40.6 & 18.8 & 19.6 & 21.0 & 40.7 & 19.5 & 19.6 & 20.2 & -0.1 & -0.7 & 0.0 & 0.8 \\
\hline
\end{tabular}

Notes

a. The voting decisions are expressed as percentages for each level of Political Orientation (adding up to 100 within the treatment group and also within the control group); the Political Orientation ranges from 1 (very left wing) to 7 (very right wing).

b. The percentages for the seven levels of Political Orientation are obtained from multinomial logit models, and those for "All" by aggregating the results for the seven political orientation levels by means of the sample percentages (in the ex ante treatment and control groups).

c. The last four "Difference" columns show the estimated treatment effects, that is, the differences in estimated percentages between the treatment and control groups; differences of more than $5 \%$ (in absolute value) are underlined.

d. Intention for voting is measured by the Fitted Voting Intention (FVI), computed from Voting Attitude, Previous Voting, and Political Interest; FVI "high" is defined by FVI = 5.5 (about one standard deviation below the maximum), and "low" by FVI = 2.5 (about one standard deviation above the minimum;

FVI in the combined ex ante treatment group and ex post control group has minimum 1.39, maximum 6.67, and standard deviation 1.36). 


\section{Detailed Results}

The tables with detailed results concern data (Tables 5 and 6), models (Tables 7, 8, and 9), and technical results (Tables 10-13).

\section{Data Tables}

- Table 5: Descriptive statistics of population and of treatment and control samples.

- Table 6: Comparison of treatment and control groups.

\section{Model Tables}

- Table 7: Model for voting intention.

- Table 8: Two models for voting participation probability.

- Table 9: Two models for treatment effects on voting participation and party choice.

\section{Technical Results Tables}

- Table 10: Estimated voting decision probabilities and treatment effects. (Technical results related to Table 4.)

10.A: Estimated voting decision probabilities and treatment effects obtained from the models in Table 9.

10.B: Estimated voting decision probabilities and treatment effects obtained in a preliminary pilot study.

- Table 11: Estimated models for voting intention, and mean fitted intention per group. (Technical results related to Table 7.)

11.A: Estimated models for voting intention.

11.B: Tests on differences in mean FVI per political orientation group.

11.C: Mean fitted voting intention per group (political orientation and voting decision).

- Table 12: Estimation of voting participation probabilities. (Technical results related to Table 8.)

12.A: Estimation of voting participation probabilities.

12.B: Rivers-Vuong test for measurement errors.

12.C: Voting Intention and Fitted Voting Intention in treatment group.

- Table 13: Treatment effects on voting participation and party choice. (Technical results related to Table 9.) 
Table 5: Descriptive statistics of population and of treatment and control samples

\begin{tabular}{llccccc}
\hline \hline & & Netherlands & $\begin{array}{c}\text { Ex ante } \\
\text { Treatment }\end{array}$ & $\begin{array}{c}\text { Ex ante } \\
\text { Control }\end{array}$ & $\begin{array}{c}\text { Ex post } \\
\text { Treatment }\end{array}$ & $\begin{array}{c}\text { Ex post } \\
\text { Control }\end{array}$ \\
\hline Sample size & & & 549 & 507 & 357 & 223 \\
Gender & Male & 49.5 & 58.8 & 55.4 & 56.3 & 58.7 \\
Age & $18-39$ & 34.3 & 52.6 & 49.9 & 53.2 & 48.9 \\
& $40-59$ & 37.0 & 35.0 & 37.2 & 33.9 & 39.0 \\
\multirow{5}{*}{ Education } & L0+ & 28.7 & 12.4 & 12.8 & 12.9 & 12.1 \\
& Low & 36.6 & 42.9 & 42.8 & 41.7 & 39.9 \\
& Middle & 33.6 & 22.4 & 16.8 & 23.5 & 17.9 \\
& High & 29.7 & 34.7 & 40.4 & 34.8 & 42.2 \\
\hline \hline
\end{tabular}

Notes

1. Table numbers for Gender, Age, and Education refer to percentage shares of each group.

2. Data for the Netherlands are taken (or derived) from the Statline Databank of the Central Bureau of Statistics (summer 2009).

3. Education is defined as low for at most secondary school ("vwo"), and as high for at least higher vocational education ("hbo"). 


\section{Table 6: Comparison of treatment and control groups}

\begin{tabular}{lllcccc}
\hline \hline & Scale & Measure & $\begin{array}{c}\text { Ex ante } \\
\text { Treatment }\end{array}$ & $\begin{array}{c}\text { Ex ante } \\
\text { Control }\end{array}$ & $\begin{array}{c}\text { Ex post } \\
\text { Treatment }\end{array}$ & $\begin{array}{c}\text { Ex post } \\
\text { Control }\end{array}$ \\
\hline Sample size & & count & 549 & 507 & 357 & 223 \\
Voting Intention & $1-7$ (no - yes) & mean & 5.3 &. & 5.3 &. \\
Voting Attitude & $1-5$ (no - yes) & mean & 4.2 &. & 4.2 & 4.1 \\
Previous Voting & $1-5$ (no - yes) & mean & 3.7 &. & 3.8 & 3.8 \\
Political Interest & $1-5$ (no - yes) & mean & 3.3 &. & 3.3 & 3.4 \\
Political Orientation & $1-7$ (left - right) & mean & 4.0 & 4.0 & 4.0 & 4.0 \\
& left (1-3) & $\%$ & 35.8 & 35.5 & 34.7 & 37.7 \\
& middle (4) & $\%$ & 26.7 & 30.0 & 28.3 & 24.1 \\
& right (5-7) & $\%$ & 37.4 & 34.6 & 37.0 & 38.2 \\
Party Choice & $1-8$ (left - right) & mean & 4.8 &. & 4.7 & 4.6 \\
(intended or actual) & left (1-3) & $\%$ & 31.2 &. & 30.4 & 34.7 \\
& middle (4-5) & $\%$ & 33.0 &. & 33.8 & 31.4 \\
& right (6-8) & $\%$ & 35.9 &. & 35.7 & 33.9 \\
Vote & $0-1$ (no - yes) & $\%$ &. &. & 63.0 & 60.1 \\
& of left oriented & $\%$ &. &. & 71.0 & 54.2 \\
& of middle oriented & $\%$ &. &. & 48.5 & 56.6 \\
& of right oriented & $\%$ &. &. & 66.7 & 66.7 \\
\hline \hline
\end{tabular}

Notes

1. See Table 1 with the survey questions for more information on the variables.

2. For Voting Attitude and Previous Voting, people are excluded who were not yet allowed to vote at previous elections (10.5\% for Voting Attitude and 14.3\% for Previous Voting).

3. For Party Choice, this is the intended party for the ex ante treatment group and the actual party for both ex post groups.

4. For Party Choice, people are excluded who answered by "I don't know or I don't wish to say" (35.4\% ex ante, 3.6\% ex post), or by "I vote for another party" (1.7\% ex ante, 3.6\% ex post). 


\section{Table 7: Model for voting intention}

\begin{tabular}{lcc}
\hline \hline Variable & coeff & p-value \\
\hline Constant & -1.04 & 0.01 \\
Voting Attitude & 0.80 & 0.00 \\
Previous Voting & 0.32 & 0.00 \\
Political Interest & 0.21 & 0.01 \\
\hline Sample size & 464 & \\
R-squared & 0.43 & \\
\hline \hline
\end{tabular}

\section{Notes}

1. The explained variable is Voting Intention, and the coefficients are estimated by least squares.

2. The sample is restricted to people in the ex ante treatment group who were allowed to vote at the previous elections.

3. The Fitted Voting Intention (FVI) is computed for anyone with given scores for Voting Attitude, Previous Voting, and Political Interest. 
Table 8: Two models for voting participation probability

\begin{tabular}{lcccc}
\hline \hline Model & 1 & & 2 & \\
Variable & coeff & p-value & coeff & p-value \\
\hline Constant & -9.78 & 0.00 & -0.53 & 0.27 \\
FVI & 1.77 & 0.00 & & 0.02 \\
Treatment & 6.98 & 0.00 & 1.35 & 0.02 \\
Treatment * FVI & -1.04 & 0.00 & & 0.02 \\
Political Orientation & 0.32 & 0.04 & 0.27 & -0.33 \\
Treatment * (Political Orientation) & -0.44 & 0.02 & 495 & 0.01 \\
\hline Sample size & 495 & & & \\
McFadden R-squared & 0.25 & & & \\
\hline \hline
\end{tabular}

\section{Notes}

1. The explained variable is Vote, and the coefficients are estimated by means of a binary logit model.

2. FVI is the Fitted Voting Intention, obtained from Table 7 in terms of Voting Attitude, Previous Voting, and Political Interest. 
Table 9: Two models for treatment effects on voting participation and party choice

\begin{tabular}{|c|c|c|c|c|c|c|}
\hline \multicolumn{3}{|l|}{ Model } & \multicolumn{2}{|l|}{ 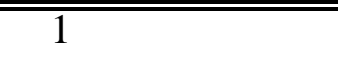 } & \multicolumn{2}{|l|}{$\overline{2}$} \\
\hline Choice & Group & Variable & coeff & $\mathrm{p}$-value & coeff & $\mathrm{p}$-value \\
\hline \multirow[t]{6}{*}{ Left } & Treatment & Constant & -3.55 & 0.00 & 2.51 & 0.00 \\
\hline & & FVI & 1.17 & 0.00 & 0 & \\
\hline & & Political Orientation & -1.02 & 0.00 & -0.99 & 0.00 \\
\hline & Control & Constant & -4.91 & 0.00 & 1.02 & 0.05 \\
\hline & & FVI & 1.17 & 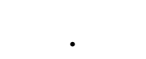 & 0 & \\
\hline & & Political Orientation & -0.50 & 0.00 & -0.50 & 0.00 \\
\hline \multirow[t]{2}{*}{ Middle } & Both & Constant & -5.74 & 0.00 & -0.73 & 0.00 \\
\hline & & FVI & 0.99 & 0.00 & 0 & \\
\hline \multirow[t]{6}{*}{ Right } & Treatment & Constant & -6.34 & 0.00 & -3.75 & 0.00 \\
\hline & & FVI & 0.56 & 0.00 & 0 & \\
\hline & & Political Orientation & 0.63 & 0.00 & 0.68 & 0.00 \\
\hline & Control & Constant & -13.35 & 0.00 & -3.75 & . \\
\hline & & FVI & 1.84 & 0.00 & 0 & \\
\hline & & Political Orientation & 0.63 & . & 0.68 & . \\
\hline \multicolumn{2}{|c|}{ Sample size } & & 469 & & 546 & \\
\hline \multicolumn{2}{|c|}{ Log-likelihood } & & -487 & & -647 & \\
\hline \multicolumn{2}{|c|}{ Avg. Log-lik. } & & -1.04 & & -1.19 & \\
\hline
\end{tabular}

Notes

1. The explained variable (voting decision) is multinomial, with reference choice "not vote" and as other options to vote for a left, middle, or right wing party; the coefficients are estimated in a multinomial logit model.

2. The Fitted Voting Intention (FVI) is obtained from Table 7; FVI is excluded in Model 2.

3. The models are obtained from more elaborate ones, after removing insignificant effects; for instance, the treatment effect is not significant for the choice "middle".

4. A dotted (.) p-value is for a parameter in the control group that is equal to that in the treatment group; in Model 2, the zero (0) coefficients for FVI mean that this variable is excluded a priori from the model. 
Table 10: Estimated voting decision probabilities and treatment effects (Technical details related to Table 4)

Table 10.A: Estimated voting decision probabilities and treatment effects obtained from the models in Table 9 (denoted by Model 9.1 and 9.2)

\begin{tabular}{|c|c|c|c|c|c|c|c|c|c|c|c|c|c|c|c|}
\hline \multirow[b]{2}{*}{ Model } & \multirow[b]{2}{*}{ Intention } & \multirow[b]{2}{*}{ Pol. Or. } & \multirow[b]{2}{*}{ Sample \% } & \multicolumn{2}{|c|}{ Treatment } & \multirow[b]{2}{*}{ Middle } & \multirow[b]{2}{*}{ Right } & \multicolumn{2}{|c|}{ Control } & \multirow[b]{2}{*}{ Middle } & \multirow[b]{2}{*}{ Right } & \multicolumn{4}{|c|}{ "Difference (Treatment - Control) } \\
\hline & & & & Not & Left & & & Not & Left & & & Not & Left & Middle & Right \\
\hline \multirow[t]{14}{*}{$\begin{array}{l}9.1 \\
\end{array}$} & Low & 1 & 2 & 80.3 & 15.5 & 3.1 & 1.1 & 89.1 & 7.4 & 3.4 & 0.0 & $\underline{-8.8}$ & 8.1 & -0.3 & 1.1 \\
\hline & & 2 & 16 & 88.3 & 6.1 & 3.4 & 2.2 & 91.8 & 4.6 & 3.5 & 0.1 & $\overline{-3.5}$ & $\overline{1.5}$ & -0.1 & 2.2 \\
\hline & & 3 & 18 & 90.0 & 2.3 & 3.4 & 4.3 & 93.5 & 2.9 & 3.6 & 0.1 & -3.4 & -0.6 & -0.1 & 4.2 \\
\hline & & 4 & 28 & 88.0 & 0.8 & 3.4 & 7.8 & 94.5 & 1.8 & 3.6 & 0.2 & $\underline{-6.4}$ & -1.0 & -0.2 & $\underline{7.6}$ \\
\hline & & 5 & 19 & 82.8 & 0.3 & 3.2 & 13.8 & 95.0 & 1.1 & 3.6 & 0.4 & $-\overline{-12.2}$ & -0.8 & -0.5 & $\overline{13.5}$ \\
\hline & & 6 & 15 & 73.9 & 0.1 & 2.8 & 23.2 & 95.1 & 0.7 & 3.6 & 0.7 & -21.1 & -0.6 & -0.8 & $\underline{22.5}$ \\
\hline & & 7 & 2 & 61.5 & 0.0 & 2.3 & 36.2 & 94.8 & 0.4 & 3.6 & 1.2 & -33.3 & -0.4 & -1.3 & $\underline{34.9}$ \\
\hline & High & 1 & 2 & 12.1 & 78.0 & 9.0 & 0.9 & 21.7 & 60.5 & 16.2 & 1.6 & $\underline{-9.6}$ & $\underline{17.5}$ & $\underline{-7.2}$ & $\overline{-0.7}$ \\
\hline & & 2 & 16 & 23.8 & 55.3 & 17.7 & 3.2 & 28.0 & 47.3 & 20.8 & 3.9 & -4.2 & $\underline{8.0}$ & -3.1 & -0.7 \\
\hline & & 3 & 18 & 35.2 & 29.6 & 26.2 & 9.0 & 33.0 & 33.8 & 24.6 & 8.6 & 2.3 & -4.2 & 1.7 & 0.3 \\
\hline & & 4 & 28 & 39.6 & 12.0 & 29.5 & 18.9 & 35.0 & 21.8 & 26.1 & 17.2 & 4.6 & $\underline{-9.8}$ & 3.4 & 1.7 \\
\hline & & 5 & 19 & 36.4 & 4.0 & 27.1 & 32.6 & 32.8 & 12.4 & 24.5 & 30.3 & 3.5 & $\underline{-8.4}$ & 2.6 & 2.3 \\
\hline & & 6 & 15 & 28.9 & 1.1 & 21.5 & 48.5 & 27.0 & 6.2 & 20.1 & 46.8 & 1.9 & $\underline{-5.0}$ & 1.4 & 1.8 \\
\hline & & 7 & 2 & 20.3 & 0.3 & 15.1 & 64.2 & 19.5 & 2.7 & 14.5 & 63.3 & 0.9 & -2.4 & 0.7 & 0.9 \\
\hline \multirow[t]{6}{*}{9.1} & Low & Left (1--3) & 36 & 88.7 & 4.7 & 3.4 & 3.2 & 92.5 & 3.9 & 3.5 & 0.1 & -3.8 & 0.8 & -0.1 & 3.1 \\
\hline & & Middle (4) & 28 & 88.0 & 0.8 & 3.4 & 7.8 & 94.5 & 1.8 & 3.6 & 0.2 & $\underline{-6.4}$ & -1.0 & -0.2 & 7.6 \\
\hline & & Right (5--7) & 36 & 78.0 & 0.2 & 3.0 & 18.8 & 95.0 & 0.9 & 3.6 & 0.5 & $-\overline{-16.9}$ & -0.7 & -0.6 & $\underline{18.3}$ \\
\hline & High & Left & 36 & 28.8 & 43.8 & 21.4 & 5.9 & 30.1 & 41.4 & 22.4 & 6.1 & $\overline{-1.3}$ & 2.5 & -1.0 & $\overline{-0.2}$ \\
\hline & & Middle & 28 & 39.6 & 12.0 & 29.5 & 18.9 & 35.0 & 21.8 & 26.1 & 17.2 & 4.6 & $\underline{-9.8}$ & 3.4 & 1.7 \\
\hline & & Right & 36 & 32.5 & 2.6 & 24.2 & 40.8 & 29.7 & 9.3 & 22.1 & 38.8 & 2.7 & -6.7 & 2.0 & 2.0 \\
\hline \multirow[t]{2}{*}{9.1} & Low & All (1--7) & 100 & 84.7 & 2.0 & 3.2 & 10.1 & 93.9 & 2.2 & 3.6 & 0.3 & $\underline{-9.3}$ & -0.2 & -0.4 & $\underline{9.9}$ \\
\hline & High & All & 100 & 33.2 & 20.0 & 24.7 & 22.2 & 31.4 & 24.3 & 23.3 & 21.0 & 1.8 & -4.3 & 1.4 & 1.1 \\
\hline \multirow[t]{7}{*}{9.2} & Excluded & 1 & 2 & 16.4 & 74.9 & 7.9 & 0.8 & 31.1 & 52.4 & 15.0 & 1.4 & -14.8 & $\underline{22.6}$ & -7.1 & -0.7 \\
\hline & & 2 & 16 & 30.6 & 51.9 & 14.7 & 2.8 & 38.6 & 39.3 & 18.6 & 3.5 & -8.0 & $\underline{12.6}$ & $\overline{-3.9}$ & -0.7 \\
\hline & & 3 & 18 & 43.6 & 27.5 & 21.0 & 7.9 & 43.8 & 27.1 & 21.1 & 7.9 & $\overline{-0.2}$ & $\overline{0.4}$ & -0.1 & 0.0 \\
\hline & & 4 & 28 & 48.2 & 11.3 & 23.2 & 17.2 & 45.2 & 16.9 & 21.8 & 16.1 & 3.1 & $\underline{-5.6}$ & 1.5 & 1.1 \\
\hline & & 5 & 19 & 44.0 & 3.8 & 21.2 & 31.0 & 41.4 & 9.4 & 20.0 & 29.2 & 2.6 & -5.6 & 1.2 & 1.8 \\
\hline & & 6 & 15 & 34.4 & 1.1 & 16.6 & 47.9 & 33.2 & 4.6 & 16.0 & 46.2 & 1.2 & -3.5 & 0.6 & 1.7 \\
\hline & & 7 & 2 & 23.6 & 0.3 & 11.4 & 64.8 & 23.2 & 1.9 & 11.2 & 63.7 & 0.4 & -1.7 & 0.2 & 1.1 \\
\hline \multirow[t]{3}{*}{9.2} & Excluded & Left (1--3) & 36 & 36.2 & 41.1 & 17.5 & 5.2 & 40.8 & 34.0 & 19.6 & 5.6 & -4.5 & 7.1 & -2.2 & -0.4 \\
\hline & & Middle (4) & 28 & 48.2 & 11.3 & 23.2 & 17.2 & 45.2 & 16.9 & 21.8 & 16.1 & 3.1 & $\underline{-5.6}$ & 1.5 & 1.1 \\
\hline & & Right (5--7) & 36 & 39.0 & 2.5 & 18.8 & 39.7 & 37.1 & 7.0 & 17.9 & 38.0 & 1.9 & -4.5 & 0.9 & 1.7 \\
\hline 9.2 & Excluded & All (1--7) & 100 & 40.6 & 18.8 & 19.6 & 21.0 & 40.7 & 19.5 & 19.6 & 20.2 & -0.1 & -0.7 & 0.0 & 0.8 \\
\hline
\end{tabular}


Notes for Table 10.A

1. The voting decision probabilities are expressed as percentages for each level of Political Orientation (adding up to 100 within the treatment group and also within the control group); the Political Orientation ranges from 1 (very left wing) to 7 (very right wing)

2. The probabilities for 7 levels of Political Orientation are obtained from Table 9, and those for 3 levels or a single level by aggregating the results for left wing and for right wing oriented people by means of the sample percentages of these political orientation groups (in the ex ante treatment and control groups); the sample percentages are shown in the table.

3. The "Difference" columns show the treatment effects, that is, the differences in estimated probabilities between the treatment and control groups; these differences are obtained from the results in Table 9, which includes effects only if they are significant.

4. Intention for voting is measured by the Fitted Voting Intention (FVI) obtained form Table 7; FVI "high" is defined by FVI = 5.5 (about one standard deviation below the maximum), and "low" by FVI = 2.5 (about one standard deviation above the minimum; FVI in the combined ex ante treatment group and ex post control group has minimum 1.39, maximum 6.67, and standard deviation 1.36).

5. As a technical note, the probabilities to choose for any of the four available options (not to vote, or to vote for a left, middle, or right wing party), are obtained from the multinomial logit models in Table 9; for a given (treatment or control) group, let XL, XM, and XR be the weighted average of th€ explanatory variables, with weights equal to the coefficients for the choice for respectively left, middle and right (for example, for Model 9.1 and for the Treatment group, XL = -3.55 + 1.17*FVI -1.02*PolOr); let EL= exp(XL), EM = exp(XM), ER = exp(XR), and EALL = $1+$ EL + EM + ER, then the logit model states that Prob(Not Vote) $=1 /$ EALL, Prob(Left Vote) $=$ EL/EALL, Prob(Middle Vote) $=$ EM/EALL, and Prob(Right Vote) $=$ ER/EALL)

\section{Table 10.B: Estimated voting decision probabilities and treatment effects obtained in a preliminary pilot study}

\begin{tabular}{lccccccccc}
\hline \hline & Treatment & \multicolumn{3}{c}{ Control } & \multicolumn{4}{c}{ Difference } \\
Pol. Or. & Not & Left & Right & Not & Left & Right & Not & Left & Right \\
\hline 1 & 1.4 & 98.6 & 0.0 & 1.8 & 98.2 & 0.0 & -0.4 & 0.4 & 0.0 \\
2 & 9.8 & 90.0 & 0.1 & 20.5 & 79.4 & 0.0 & $\underline{-10.7}$ & $\underline{10.6}$ & 0.1 \\
3 & 44.2 & 52.5 & 3.3 & 77.2 & 20.9 & 1.8 & $\underline{-33.0}$ & $\underline{\underline{31.6}}$ & 1.4 \\
4 & 65.1 & 10.0 & 24.9 & 65.8 & 1.3 & 32.9 & $\underline{-0.8}$ & $\underline{8.8}$ & $\underline{-8.0}$ \\
5 & 33.2 & 0.7 & 66.1 & 8.7 & 0.0 & 91.3 & $\underline{\underline{24.5}}$ & 0.7 & $\underline{\underline{-25.2}}$ \\
6 & 8.8 & 0.0 & 91.1 & 0.5 & 0.0 & 99.5 & $\underline{8.4}$ & 0.0 & $\underline{-8.4}$ \\
7 & 1.8 & 0.0 & 98.2 & 0.0 & 0.0 & 100.0 & 1.8 & 0.0 & -1.8 \\
\hline \hline
\end{tabular}

Notes

1. The pilot study is based on regional elections in the Netherlands in 2007; the joined ex post treatment and control samples contain 129 observations.

2. The results in the table are obtained in a similar way as the ones in Table 10.A for Model 9.2; due to the small sample size, the relatively more

left-wing middle party was joined with the other left wing parties, and the other, more right-wing middle party was joined with the other right winধ parties; some very small parties with unclear political orientation were joined with the option "not vote"; hence, a three-option multinomial logit

model (not vote, left vote, or right vote) is applied (instead of the four-option models in Table 9)

3. More details on this pilot study are given in a working paper that can be obtained from the authors. 
Table 11: Estimated models for voting intention, and mean fitted intention per group (Technical details related to Table 7)

Table 11.A: Estimated models for voting intention

\begin{tabular}{|c|c|c|c|c|c|c|c|c|c|}
\hline$\overline{\text { Model }}$ & 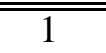 & & & 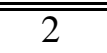 & & & 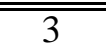 & & \\
\hline Variable & coeff & t-value & p-value & coeff & t-value & p-value & coeff & t-value & p-value \\
\hline Constant & -0.72 & -1.97 & 0.05 & -1.04 & -2.68 & 0.01 & -0.92 & -2.09 & 0.04 \\
\hline Voting Attitude & 0.86 & 9.59 & 0.00 & 0.80 & 8.64 & 0.00 & 0.79 & 8.54 & 0.00 \\
\hline Previous Voting & 0.33 & 5.79 & 0.00 & 0.32 & 5.59 & 0.00 & 0.32 & 5.58 & 0.00 \\
\hline Political Interest & & & & 0.21 & 2.55 & 0.01 & 0.21 & 2.51 & 0.01 \\
\hline Political Orientation & & & & & & & -0.03 & -0.50 & 0.62 \\
\hline Sample size & 464 & & & 464 & & & 463 & & \\
\hline R-squared & 0.42 & & & 0.43 & & & 0.42 & & \\
\hline
\end{tabular}

Notes

1. The explained variable is Voting intention, and the coefficients are estimated by least squares.

2. The sample is restricted to people in the ex ante treatment group who were allowed to vote at the previous elections.

3. Model 2 will be used to compute the FVI (Fitted Voting Intention) from the three variables of this model, see Table 7.

\section{Table 11.B: Tests on differences in mean FVI per political orientation group}

\begin{tabular}{lccc}
\hline \hline Variable & coeff & t-value & p-value \\
\hline Constant & 4.99 & 25.17 & 0.00 \\
(1) Treatment & 0.06 & 0.25 & 0.80 \\
(2) Left Pol. Or. & 0.09 & 0.36 & 0.72 \\
(3) Right Pol. Or. & 0.42 & 1.64 & 0.10 \\
(4) Treatment * (Left Pol. Or.) & 0.25 & 0.82 & 0.41 \\
(5) Treatment * (Right Pol. Or.) & -0.03 & -0.10 & 0.92 \\
\hline Sample size & 651 & & \\
R-squared & 0.02 & & \\
\hline \hline
\end{tabular}


Notes for Table 11.B

1. The explained variable is FVI, the fitted voting intention obtained from Model 2 in Table 11.A; Treatment and Political Orientation are expressed as dummy variables (with Control and Middle orientation as reference groups).

2. The sample consists of all people for whom FVI can be computed (that is, for whom the information of the explanatory variables in Model 2 in Table 11.A is available).

3. The coefficients are estimated by least squares; this corresponds to a two-factor ANOVA with factors Treatment (2 groups) and Political Orientation (3 groups).

4. ANOVA tests: no treatment effect (coefficients 1,4 , and 5 are 0 ): p-value 0.46 ; no political orientation effect (coefficients 2, 3, 4, and 5 are 0): p-value 0.05; no interaction (coefficients 4 and 5 are 0): p-value 0.55 .

\section{Table 11.C: Mean fitted voting intention per group (political orientation and voting decision)}

\begin{tabular}{|c|c|c|c|c|c|c|c|c|c|c|c|c|}
\hline \multirow[t]{2}{*}{ Political Orientation } & \multicolumn{4}{|c|}{ Votes in Treatment group } & \multicolumn{4}{|c|}{ Votes in Control group } & \multicolumn{4}{|c|}{ "Difference (Treatment - Control) } \\
\hline & Not & Left & Middle & Right & Not & Left & Middle & Right & Not & Left & Middle & Right \\
\hline Left & 4.61 & 5.85 & 5.75 & 5.01 & 4.19 & 5.97 & 5.69 & 5.75 & 0.42 & -0.12 & 0.06 & -0.74 \\
\hline Middle & 4.36 & 5.98 & 5.83 & 5.22 & 3.62 & 5.41 & 5.67 & 5.92 & 0.74 & 0.57 & 0.16 & -0.70 \\
\hline Right & 4.94 & 6.25 & 6.01 & 5.89 & 3.98 & 5.81 & 5.67 & 6.15 & 0.96 & 0.44 & 0.34 & -0.26 \\
\hline Total & 4.62 & 5.89 & 5.87 & 5.68 & 3.99 & 5.89 & 5.68 & 6.05 & $0.63 *$ & 0.00 & 0.19 & $-0.37 *$ \\
\hline
\end{tabular}

Notes

1. Table numbers show the mean FVI (computed from Model 2 in Table 11.A) for each group.

2. In the treatment group, FVI is computed from the ex ante sample, and in the control group, FVI is computed from the ex post sample.

3. A * denotes a difference between the treatment and control groups that is significant at a 5\% significance level. 
Table 12: Estimation of voting participation probabilities (Technical details related to Table 8)

Table 12.A: Estimation of voting participation probabilities

\begin{tabular}{|c|c|c|c|c|c|c|c|c|c|c|c|c|}
\hline \multirow{2}{*}{$\begin{array}{l}\text { Model } \\
\text { Variable }\end{array}$} & \multirow{2}{*}{$\begin{array}{c}1 \\
\text { coeff }\end{array}$} & \multicolumn{4}{|c|}{2} & \multicolumn{3}{|c|}{3} & \multicolumn{3}{|c|}{4} & \multirow[b]{2}{*}{ p-value } \\
\hline & & z-value & p-value & coeff & z-value & p-value & coeff & z-value & p-value & coeff & z-value & \\
\hline Constant & -4.38 & -8.34 & 0.00 & -7.61 & -6.31 & 0.00 & -0.53 & -1.10 & 0.27 & -9.78 & -6.24 & 0.00 \\
\hline FVI & 0.95 & 9.72 & 0.00 & 1.61 & 6.91 & 0.00 & & & & 1.77 & 6.88 & 0.00 \\
\hline Treatment & & & & 4.40 & 3.28 & 0.00 & 1.35 & 2.26 & 0.02 & 6.98 & 4.10 & 0.00 \\
\hline Treatment $*$ FVI & & & & -0.89 & -3.48 & 0.00 & & & & -1.04 & -3.72 & 0.00 \\
\hline Political Orientation & & & & & & & 0.27 & 2.38 & 0.02 & 0.32 & 2.01 & 0.04 \\
\hline Treatment * (Political & ation) & & & & & & -0.33 & -2.33 & 0.02 & -0.44 & -2.34 & 0.02 \\
\hline Sample size & 498 & & & 498 & & & 495 & & & 495 & & \\
\hline McFadden R-squared & 0.21 & & & 0.24 & & & 0.01 & & & 0.25 & & \\
\hline
\end{tabular}

Notes

1. The explained variable is Vote, and the coefficients are estimated by means of a binary logit model.

2. FVI is the Fitted Voting Intention obtained from Table 7.

3. Models 3 and 4 will be used as a basis to evaluate treatment effects on party choice, see Table 8 .

\section{Table 12.B: Rivers-Vuong test for measurement errors}

\begin{tabular}{lccc}
\hline \hline Variable & coeff & z-value & p-value \\
\hline Constant & -2.13 & -5.92 & 0.00 \\
Voting Intention & 0.47 & 7.20 & 0.00 \\
Residual of Vote Intention & -0.12 & -1.57 & 0.12 \\
\hline Sample size & 307 & & \\
McFadden R-squared & 0.27 & & \\
\hline \hline
\end{tabular}


Notes for Table 12.B

1. The explained variable is Vote, and the coefficients are estimated by means of a binary probit model.

2. The "Residual of Vote Intention" is the residual obtained from the model in Table 7.

3. The sample is restricted to people in the ex post treatment group who were allowed to vote at the previous elections.

4. Rivers and Vuong (Journal of Econometrics 39, 1988, pp. 347-366) suggest a test for the presence of endogeneity (due to measurement errors of the observed Vote Intention in measuring the true, latent intention to vote), which is based on the significance of the coefficient of the "Residual of Vote Intention"; as the p-value is 0.12 , no significant endogeneity is detected, motivating the use of the models in Table 12.A (without corrections for measurement error).

Table 12.C: Voting Intention and Fitted Voting Intention in treatment group

\begin{tabular}{|c|c|c|c|c|c|c|c|c|}
\hline$\overline{\text { Model }}$ & 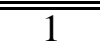 & & & & $\overline{2}$ & & & \\
\hline Variable & coeff & st.error & z-value & p-value & coeff & st.error & z-value & p-value \\
\hline Constant & -2.92 & 0.44 & -6.62 & 0.00 & -3.20 & 0.59 & -5.42 & 0.00 \\
\hline Voting Intention & 0.67 & 0.08 & 8.54 & 0.00 & & & & \\
\hline FVI & & & & & 0.72 & 0.11 & 6.59 & 0.00 \\
\hline Sample size & 307 & & & & 307 & & & \\
\hline McFadden R-squared & 0.14 & & & & 0.26 & & & \\
\hline
\end{tabular}

Notes

1. The explained variable is Vote, and the coefficients are estimated by means of a binary logit model.

2. FVI is the Fitted Voting Intention obtained from Table 7.

3. The sample is restricted to people in the ex post treatment group who were allowed to vote at the previous elections.

4. In the treatment group, Voting Intention can be used instead of FVI (whereas this is not possible for the control group, as Voting Intention is not measured in this group); as the coefficients in Models 1 and 2 do not differ significantly, FVI is used also in the treatment group (in Models 1-4 in Table 12.A), for ease of comparison with the control group. 
Table 13: Treatment effects on voting participation and party choice (Technical details related to Table 9)

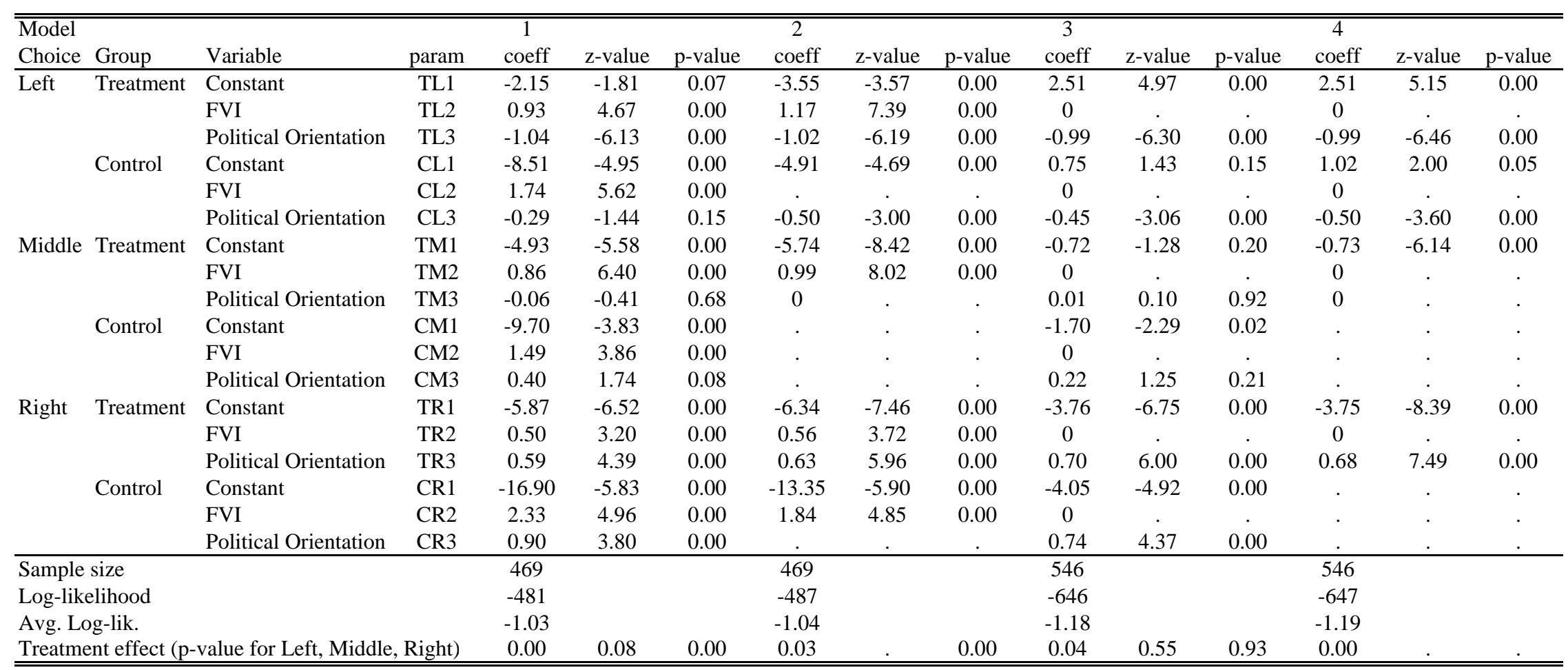

Notes

1. The explained variable (voting decision) is multinomial, with reference choice "not vote" and as other options to vote for a left, middle, or right wing party; the coefficients are estimated by means of a multinomial logit model

2. The Fitted Voting Intention (FVI) is obtained from Table 7.

3. A dot (.) denotes a parameter in the control group that is equal to that in the treatment group; a zero (0) denotes an a priori zero coefficient.

4. The bottom row of the table shows the p-value of the Wald test for the significance of treatment effects (that is, equality of the coefficients in the treatment and control group, separately for each of the three voting choices, that is, to vote for a left, middle, or right wing party).

5. Model 2 (called "Model 1" in Table 9) is a restricted version of Model 1, obtained by the following three sequential tests:

A. equal coefficients in treatment and control groups for the choice middle (TM1=CM1, TM2=CM2, TM3=CM3, p-value 0.08);

B. partial absence of treatment effects for choices left and right (TL2=CL2, TR3=CR3, p-value 0.28);

C. absence of political orientation effect for choice middle (TM3=0, p-value 0.53 ).

6. Model 4 (called "Model 2" in Table 9) is a restricted version of Model 3, obtained by the following two sequential tests:

A. equal coefficients in treatment and control groups for middle and right (TM1=CM1, TM3=CM3, TR1=CR1, TR3=CR3, p-value 0.86);

B. removal of an insignificant coefficient (TM3=0, p-value 0.37). 